\title{
AN EVALUATION METHOD FOR BUSINESS MODELS IN PRODUCT-SERVICE SYSTEMS DESIGN
}

\author{
Oh, Sanghyun (1); \\ Hong, Yoo S. (1); \\ Lee, Jihwan (2); \\ Kim, Yong Se (3)
}

1: Department of Industrial Engineering and Institute for Industrial Systems Innovation, Seoul National University;

2: Division of Systems Management and Engineering, Pukyong National University;

3: Creative Design Institute, Sungkyunkwan University

\begin{abstract}
To pursue business innovation with PSS, many different PSS concepts are designed and evaluated. Various business models of a PSS design concept are devised and evaluated as well. Evaluation of the economic sustainability of PSS business models is critical. This paper presents a systematic method to evaluate the economic sustainability of PSS business models using a system dynamics modelling template. System dynamics modelling task is challenging for practitioners due to the variety of variables comprising business model strategies and their complex interrelationships. To enable the modelling task, a system dynamics modelling template composed of six modules of customer acquisition, channel acquisition, profit creation, resource acquisition, PSS provision, and partnership pattern has been devised. The PSS business model evaluation method has been illustrated using a smart study experience management service system design case to demonstrate the proposed system dynamics modelling template can reflect the case-specific business model which consists of the particular business model strategies.
\end{abstract}

Keywords: Product-Service Systems (PSS), Business models and considerations, Sustainability, System Dynamics

\section{Contact:}

Oh, Sanghyun

Seoul National University

Industrial Engineering

Korea, Republic of (South Korea)

osh15@snu.ac.kr 


\section{INTRODUCTION}

A Product-Service Systems (PSS) is a system of products, services, supporting networks and infrastructure that is designed to satisfy customer needs and to generate values (Goedkoop et al., 1999; Tukker, 2004, 2015). Providing ecological values in addition to economic value was primary intention in early development efforts of PSS (Goedkoop et al., 1999; Tukker, 2004). Then socio-cultural aspect of services has been addressed in PSS design (Morelli, 2003). Industrial PSS developments (Meier et al., 2011) emphasized service supporting products mainly addressing economic values for manufacturing companies. Recently, efforts are being made to accommodate experiences issues as primary design goals in PSS design by reflecting characteristics of customer experiences in human-centered design approaches (Costa et al., 2018; Gemser et al., 2012; Kim et al., 2013; Kim and Hong, 2019; Valencia et al., 2015). PSS design for a circular economy is drawing a lot of attention as the environmental issue has been a main focus throughout the PSS development efforts (Fernandes et al., 2020).

As the market competition is getting more intense nowadays, the design of advanced products and services alone cannot guarantee economic sustainability (Zott et al., 2011). The latent value of product and service offerings can be unlocked through the design and implementation of a viable business model (Chesbrough, 2002). Business organizations start to spotlight the business model as a strategy to achieve superior market performance through value innovation (Teece, 2010). The business model is a logical description of how an organization creates, delivers, and captures value in the market (Osterwalder and Pigneur, 2010). Osterwalder and Pigneur (2010) developed a business model canvas consisting of nine aspects which are customer segments, customer relationship, distribution channel, value proposition, key activities, key resources, key partnerships, revenue stream, cost structure. Lee et al. (2011) proposed a set of business model strategies defined for the aspects by investigating real world business model cases. The PSS business model design methodology by using these business model strategies associated with product/service elements was introduced (Lee et al., 2011). In this paper, we adopted the above method to design PSS business model. The description of the PSS business model design methodology will be introduced in section 2 .

To pursue business innovation with PSS, many different PSS concepts are designed and evaluated. Various business models of a PSS design concept are devised and evaluated as well. Since the transition to the PSS business model involves new investments, predicting the future economic value of PSS business model concept is required. However, an evaluation method that quantitatively evaluate the dynamic economic sustainability of PSS business model is still lacking (Nakada et al., 2020).

The objective of this research is to devise a systematic method to evaluate economic sustainability of PSS business models using system dynamics simulations. PSS business models are designed by adopting diverse strategies for each aspect of the business model canvas. The system dynamics models are built in a structured manner by using a template combining six key patterns which associate adjacent aspects of the business model. The method has been validated through several PSS cases including the example case illustrated in this paper.

The paper briefly reviews the PSS business model design methodology (Lee et al., 2011) in the next section. In section 3, the system dynamics modelling using the template is explained in detail. Six patterns of the system dynamics modelling template that represents the relations of some relevant aspects are first described. Then, how these patterns are integrated into the template is described. An illustrative example PSS case is explained in section 4. Section 5 shows how the system dynamics model of the PSS business model is built from the template together with simulation results. The paper is concluded with discussions on the contribution.

\section{BUSINESS MODEL DESIGN FOR PRODUCT-SERVICE SYSTEMS}

In this section, the PSS business model design methodology (Lee et al., 2011) adopted in this paper is briefly reviewed. The PSS concept and PSS business model are designed in association with each other. The PSS business model is designed with business model canvas (Osterwalder and Pigneur, 2010) and business model strategies defined in each of aspects in the business model canvas. Under this representative business model scheme, the PSS business model is designed by selecting the relevant business model strategies associated with the product/service element for each aspect of the business model canvas (Lee et al., 2011). The key characteristic of the PSS business model design method is a set of business model strategies which were defined along with all nine aspects of the business model. Lee et al. (2011) proposed a predefined set of business model strategies which were 
defined and verified through analysing real-world successful business model cases. By examining various combinations of business model strategies associated with product/service element, the PSS business models can be designed.

\section{AN EVALUATION METHOD FOR ECONOMIC SUSTAINABILITY OF PSS BUSINESS MODEL}

In this section, an evaluation methodology for PSS business model concept's economic sustainability using system dynamics simulation is proposed. Depending on how a PSS is designed, different business models with different business model strategies are devised. These strategies and their relationship determine economic performance of the business model. Thus a methodology that can reflect, analyse, and measure the influence of strategies for each aspect and their relationship on dynamic economic performance is required. The system dynamics was developed to predict a dynamic system's performance composed of interrelationships of complex variables (Sterman, 2000). The system dynamics enables prediction of system performance from a dynamic and quantitative perspective. Therefore, the evaluation method in this paper uses system dynamics techniques.

\subsection{Evaluation process of PSS business model's economic sustainability}

The proposed evaluation process consists of system dynamics modelling of PSS business model and evaluation by simulation result analysis.

\subsubsection{Step 1: System dynamics modelling for a PSS business model}

To proceed with system dynamics modelling, it is necessary to define the variables and their relationships that make up the strategies used in each aspect. To represent the relationships of these variables in system dynamics approach, the Causal Loop Diagram (CLD) is most widely used. CLD is a causal diagram representing the variables and their influence relationship in systems (Sterman, 2000). The interrelationship of variables and their influences are represented through directional links which have positive and negative link polarity. The positive link represents that if the one variable changes to increase, the linked variable also increase. The variables and their relationships that constitute PSS business model can be represented using CLD.

To simulate the entire business model's performance, the causal diagram must be converted into a system dynamics model composed of stock variables and flow variables. The stock variable represents the system's state and represents the accumulated amount and depleted amount over time. The flow variable directly controls the stock variable, and the causal relationship of the variables surrounding the flow variable determines the overall system change over time.

Due to the complicated structures of variables and their relationships, it is hard to conduct system dynamics modelling which covers all aspects of business model canvas. To address the challenging system dynamics modelling task, a system dynamics modelling template is proposed in this paper, as detailed in section 3.2.

\subsubsection{Step 2: System dynamics simulation result analysis}

Given the initial values of the variables, dynamic economic performance of PSS business model is simulated using the system dynamics model. To evaluate PSS business model's economic performance, the appropriate key performance index (KPI) can be utilized as the criteria. For evaluating economic sustainability, the KPIs should be defined to measure how effectively stakeholder is fulfilling the economic motivations through the PSS business model. In general, KPIs for business model include metrics such as net present value (NPV), return on investment (RoI), and benefit-cost ratio (B/C Ratio). However, various KPIs can be proposed and utilized according to the PSS business model concept. For example, a PSS business model that provides the basic product for free and earns revenue from service subscriptions is appropriate to evaluate in terms of long-term revenue rather than shortterm revenue. Based on the system dynamics simulation result, the KPI values can be calculated with values of the stock and flow variables resulting from the simulation. The translation of the calculated KPIs into business insights should be performed to evaluate the designed PSS business model's economic sustainability. 


\subsection{System dynamics modelling template for PSS business model evaluation}

The core part of business model evaluation with the system dynamics approach is system dynamics modelling. The system dynamics modelling is a challenging task because the variables constituting the various PSS business model strategies from the nine aspects of business model and their influence relationship have a complex structure.

To support the complex task of system dynamics modelling, a template has been devised for PSS business model evaluation. The development of system dynamics modelling template is conducted by the definition of key patterns of PSS business model and identification of influence relationship among variables in the key patterns using CLD. The proposed system dynamics modelling template is shown in Figure 1. Using this template, the practitioners can perform the system dynamics modelling task with a little modification of variables and relationships in the template.

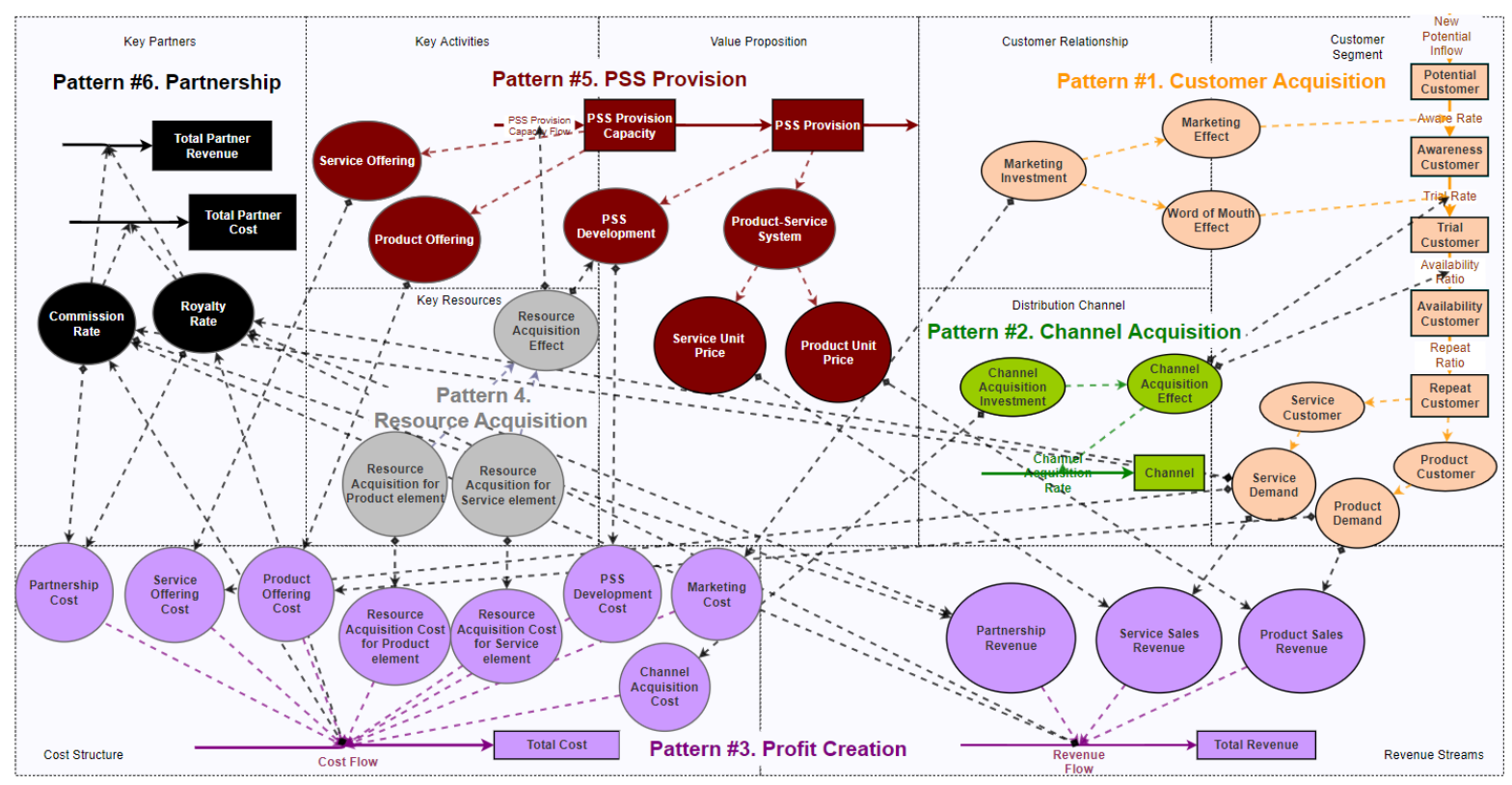

Figure 1. System dynamics modelling template

\subsubsection{Key patterns in PSS business model}

Six key patterns have been devised to address the subsets of business model aspects by divide and conquer approach (Won et al., 2014). As shown in Figure 1, the six key patterns comprehensively cover all aspects of business model canvas. The six key patterns consist of customer acquisition, channel acquisition, profit creation, resource acquisition, PSS provision, and partnership pattern. The details of the key patterns can be found in Won et al. (2014)

\subsubsection{Identification of interrelationship among key patterns}

To combine the six key patterns, we identified the interrelationships with the variables in each of key patterns and represents the relationships using CLD. The CLD consists of a set of nodes and edges. Nodes describe the variables in each of the six key patterns defined above and the edges represent a relation among them. The causal relationship between the variables in key patterns represented with the link polarity. For example, the node representing Channel Acquisition Effect variable in the channel acquisition pattern can be linked through positive polarity edge with Trial Rate variable in the customer acquisition pattern. By identifying the relationship among variables in different key patterns in this way, the interrelationship among key patterns were identified. By combining the respective key patterns by the identification of interrelationships among variables in key patterns, the template to address all the business model aspects is devised.

\subsection{Case-specific instantiation of system dynamics modelling template}

To generate the case-specific system dynamics model, the variables of each pattern in the template are instantiated to variables that reflect the strategies for each aspect. For example, if Pay per Use strategy for a service unit used in the revenue stream aspect, Service Unit Price variable in the PSS provision 
pattern in the template is instantiated to usage fee in the specific system dynamics model. Another example, if Razor-Blade strategy is used, then the Product Unit Price in the PSS provision pattern can be instantiated to Razor part price and Blade part price variables. Also, the relationship between variables in the template can be modified in instantiation process to reflect the specific business model. For example, if the policy of commission in partnership aspect is that the commission rate is proportional to revenue flows, the Commission Rate variable has relationship with Revenue Flow variable in profit creation pattern as shown in the Figure 1. However, if the policy of commission is that the commission rate is $1 \$$ for each service customer then the Commission Rate variable has relationship with Service Customer variable in the customer acquisition pattern.

Since the template is combining key patterns defined with variables that can reflect general PSS business model characteristics, the system dynamics model for the specific business model can be generated by an instantiation process with adjustment of variables and relationships. Please note that this instantiation process is to be explained in the illustrative example in section 5 in detail.

\section{ILlUStrative CASE}

LED lighting PSS has been designed with the Smart Study Experience Management (SSEM) service.

\subsection{Smart study experience management service system}

In this section, services designed in the SSEM are briefly explained so that the business model explained in the following section can be properly understood.

\subsubsection{Study activity and experience evaluation}

Study activity is an everyday contracted activity as a part of education. This activity is modelled using the Context-Based Activity Modelling (CBAM) method (Se et al., 2011) where an activity is represented with an action verb and activity elements of active actor, object, tool and context. Note that CBAM plays an important role as a schema, which is the representation and organization of information in interaction of cognitive activities in design reasoning (Park and Kim, 2007), in the personalized customization service design method (Kim et al., 2020). The study activity of a certain student without any support tools at home with the physical context of poor lighting condition may elucidate the psychological context of low motivation and poor attentiveness.

Preferred lighting conditions could be different depending on what activities a user conducts in what contexts. Also preferred lighting could be different depending on different users. In order for a specific user to find his preferred lighting for a certain activity, the user will evaluate his experiences as the user conducts the activity repeatedly under diverse lighting conditions and in many different contexts. These evaluation data need to be stored. User's subjective experience evaluations are obtained together with physical context data using the Context-specific Experience Sampling and Analysis (CESA) (Kim et al., 2011). With accumulated data of specific user's experience evaluations, most preferred lighting condition could be retrieved for a specific activity conducted under a certain context.

\subsubsection{Service units in SSEM}

Personalized Lighting Customization is a core service unit in SSEM. Learner users go to premium libraries with premium study environments including semi-private study seats. These libraries owned individually belong to franchises. Other service units are Study Planner and Community Service. Learner users plan study activities using a study companion tablet, study with lighting customization service including study experience evaluation using a tablet, review study activities and plans using a tablet inside premium libraries. Outside premium libraries, they can use Study Planner and Community Service using smart phones. The details of the personalized customization method can be found in Kim and Hong (2019).

\subsection{SSEM business model}

As PSS concepts are designed, their corresponding business models are designed. These business models are critically used in evaluating PSS design. Our business model design method is based on specific business model strategies determined for each of the aspects of the business model canvas (Osterwalder and Pigneur, 2010). By having strategies obtained from many real business cases, designers can choose relevant ones for each aspect to generate a combined business model addressing 
all relevant aspects (Lee et al., 2011). Regarding the business model strategies, each aspect will be addressed one by one. For the customer segment aspect, the Niche Targeting strategy will be selected for franchise - library owner - learner customers as the SSEM service targets those customers who would want to excel their competitors with the advanced service of SSEM. The Premium Targeting strategy is relevant for the end users not only because the SSEM service costs more financially but because the premium users who are willing to engage the more in accumulating study experience evaluation data would get the more benefits from SSEM service. The business model canvas with business model strategies identified for each aspect is shown in Figure 2. Business model strategies are shown in pink color while supplementary explanations are shown in blue.

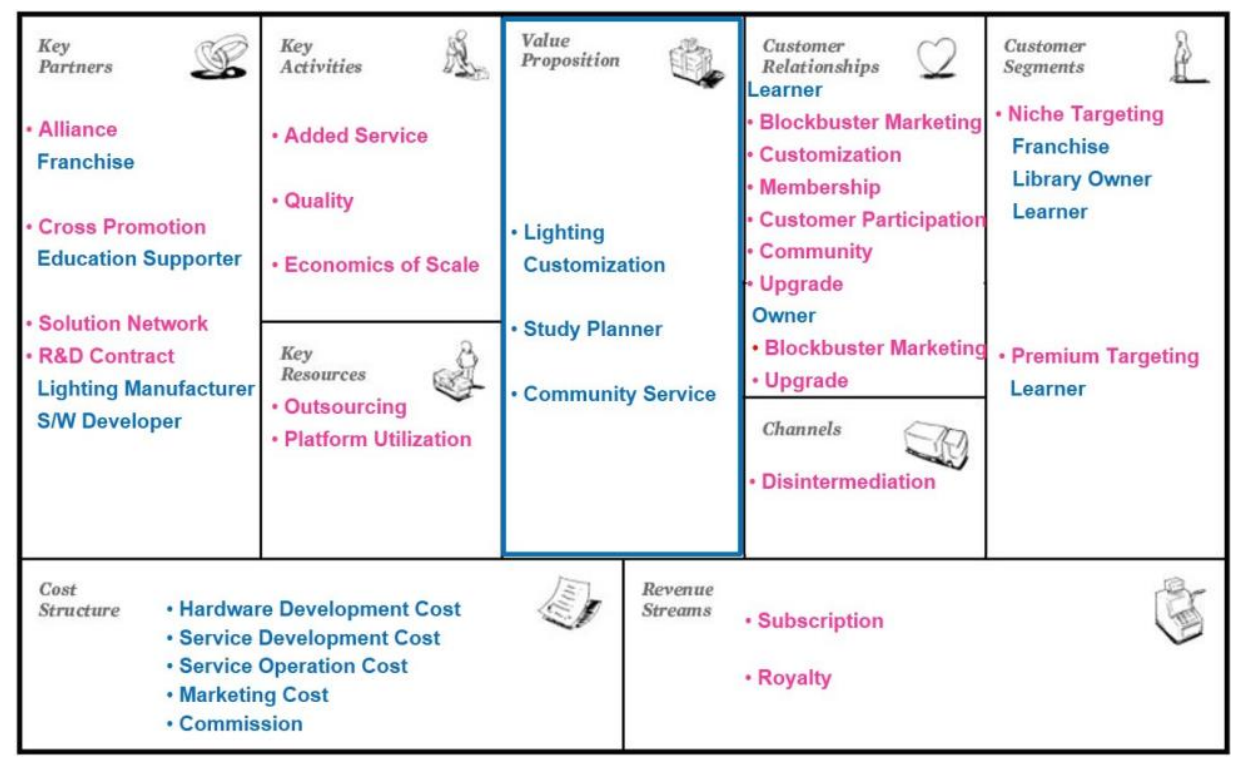

Figure 2. SSEM business model

For the customer relationship aspect, the business model strategies for learner users include Customization, Customer Participation and Upgrade reflecting the core nature of the personalized customization service using accumulated experience evaluation data. Membership and Community strategies are also relevant noting the Study Planner and Community services. With franchise headquarters involved, the Blockbuster Marketing strategy is also used. The Blockbuster Marketing and Upgrade strategies are also relevant for library owner. For the channel aspect, SSEM service is provided by direct interaction of learner users with product and service elements while it has B2B2C nature. Thus the Disintermediation strategy is used.

To provide the SSEM service composed of Lighting Customization, Study Planner and Community Service, the key activity aspect strategies are Added Service, Quality and Economics of Scale. While the SSEM service and its quality are key, the scale is also critical to lower the cost related with product elements. For the key resources aspect, Outsourcing for LED lighting hardware elements and Platform Utilization of the resources of premium library franchises are strategically important.

For the key partnership aspect, the Alliance strategy with premium library franchises are critical considering the current mega-trend in the market of private libraries. In developing the SSEM PSS, collaboration with lighting manufacturers and S/W developers in the form of $R \& D$ Contract and Solution Network is necessary. The Cross Promotion with education service providers can be pursued. In the cost structure aspect, the elements of the cost are identified as hardware (LED lighting controller) and service development costs, service operation cost, marketing cost and commission for franchises. Commission for premium library franchises is included as well as service operational cost. Revenues include Subscription by learners and Royalty from library owners are key revenue sources.

\section{EVALUATION OF ECONOMIC SUSTAINABILITY FOR SSEM BUSINESS MODEL CASE}

This section will evaluate the SSEM business model's economic sustainability through the system dynamics modelling approach. 


\subsection{System dynamics modelling for SSEM business model evaluation}

For the evaluation of SSEM business model, system dynamics modelling was performed using the template as shown in Figure 3. For SSEM business model case, the Alliance partnership strategy with franchise of premium library is used so that the distribution channel of SSEM service is the premium libraries in operating through franchises. In place of distribution channel acquisition, the commission from SSEM to franchise is incurred. Thus key patterns defined in the template except the channel acquisition pattern were used.

In this section, the instantiation process of system dynamics modelling template to SSEM case is explained. Specifically, this section explains how the variables used in each of five key patterns and their interrelationships would be addressed based on the business model strategies.

\subsubsection{SSEM customer acquisition pattern}

As seen from the customer segment aspect of the business model in Figure 2, the SSEM targets Premium and Niche customers who already use private libraries belonging to franchises. A portion of private library customers would be aware of the SSEM service, and a portion of SSEM aware customers would use SSEM service. The customer model in the template is modified to the customer model constituted with stock variables SSEM_Potential Customer, SSEM_Aawareness Customer, and SSEM_Service Usage as shown in Figure 3.

Since, the SSEM business model is designed with Subscription based Membership strategies, the Service Demand and Service Sales Revenue variables in template are used, and instantiated to SSEM Subscription Demand, SSEM_Subscription Revenue variables. Due to the SSEM PSS business model does not get any revenue from product elements, the product element-related variables in template such as Product Unit Price, Product Demand, and Product Sales Revenue were removed. In evaluating economic sustainability year by year, the SSEM_Subscription Demand variable is calculated with SSEM Yearly Usage which is flow variable.

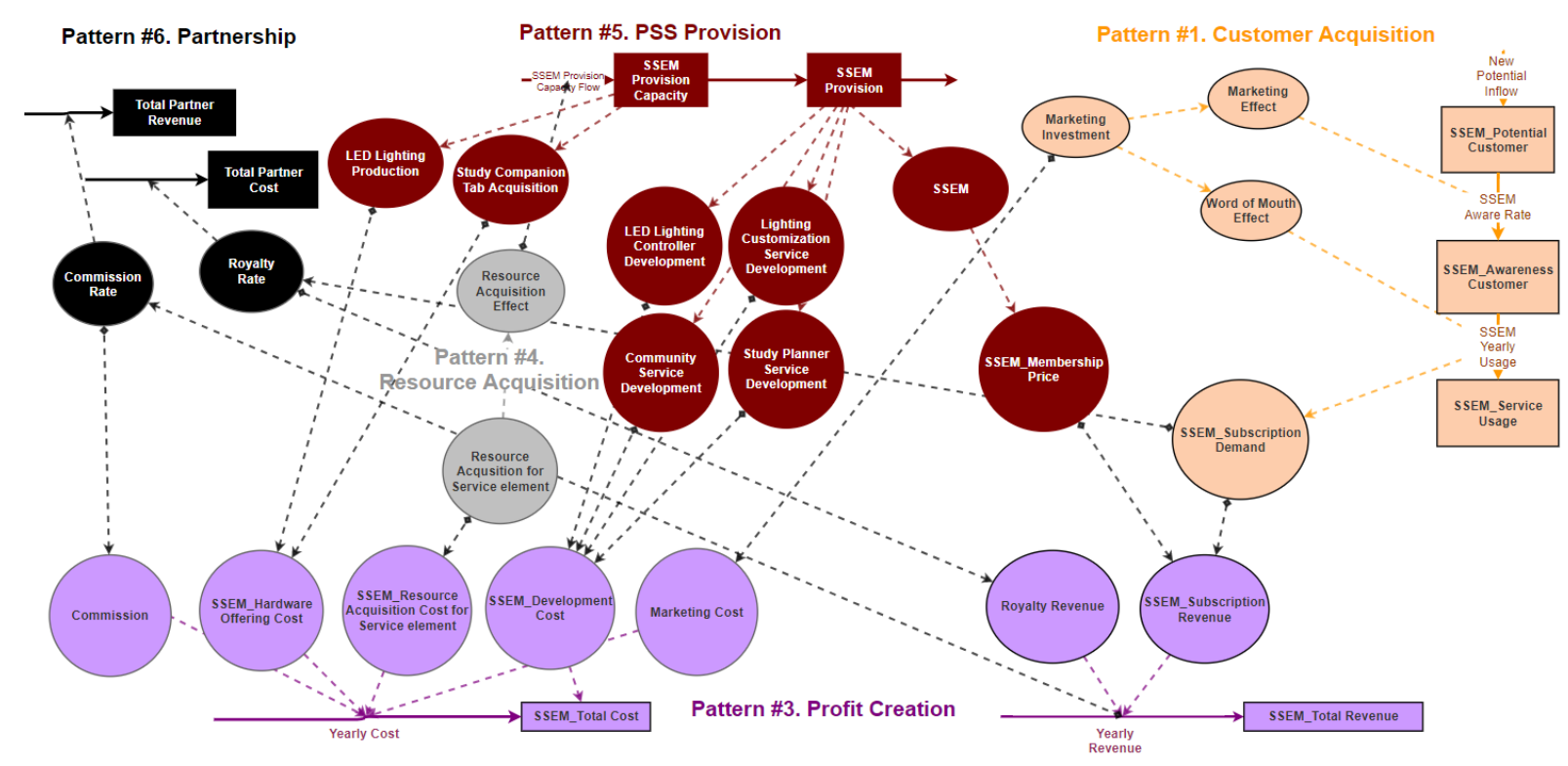

Figure 3. System dynamics model for SSEM business model evaluation

\subsubsection{SSEM PSS provision pattern}

The PSS provision pattern addresses value proposition, key activity, revenue streams and cost structure aspects. Lighting Customization, Study Planner, and Community Service are the value proposition of SSEM. For Lighting Customization, LED light controllers are to be developed. Thus the PSS Development variable in the template is instantiated to LED Lighting Controller Development, Lighting Customization Service Development, Community Service Development and Study Planner Service Development. These variables constitute SSEM_Development Cost. The SSEM development cost is assumed to arise once in development phase. The SSEM_Development Cost is linked to SSEM_Total Cost which is stock variable and set as the initial value of the variable. 
As hardware for SSEM PSS are LED lights and study companion tablets, LED Lighting Production and Study Companion Tab Acquisition variables are instantiated. These variables are linked to SSEM_Hardware Offering cost which is modelled in profit creation pattern.

As the SSEM business model is designed with Subscription based Membership strategies, the Service Unit Price variable in template is instantiated to SSEM_Membership Price variable. This SSEM_Membership Price variable constitutes SSEM_Subscription Revenue variable which is instantiated from Service Sales Revenue in the template. As light systems and tablets are not separately sold to learner users, Product Unit Price and Product Sales Revenue variables are not addressed.

\subsubsection{SSEM resource acquisition pattern}

The resource acquisition pattern associates key resources and cost structure aspects. In SSEM case, resources for SSEM service operation such as IT manager, database, servers are required to provide SSEM service. These are modelled with Resource Acquisition for Service element variable. The cost incurred from this resource acquisition is addressed with the SSEM_Resource Acquisition Cost for Service element variable in profit creation pattern.

\subsubsection{SSEM partnership pattern}

The SSEM company offers SSEM service to members who already use the premium library. In this model, the SSEM company invests the required product elements for SSEM PSS, and creates revenue partially from royalty fee from the premium libraries. To reflect this partnership, Royalty Rate in partnership pattern is modelled and linked to Royalty Revenue variable in profit creation pattern. Also, the SSEM company has partnership with premium library franchises to distribute the service and to manage overall customer relationship using the Blockbuster Marketing strategy, the commission from SSEM to franchise is incurred. In SSEM business model, since the commission fee is proportional to yearly revenue, the Commission Rate variable is linked to Yearly Revenue variable which is a flow variable in profit creation pattern.

\subsubsection{SSEM profit creation pattern}

As the revenue stream aspect in SSEM business model involves Subscription and Royalty strategy, SSEM_Subscription Revenue and Royalty Revenue variables which are instantiated from Service Sales Revenue and Partnership Revenue variables in the template. The SSEM_Subscription Revenue is calculated with SSEM_Membership Price in PSS provision and SSEM_Subscription Demand in customer acquisition pattern. The SSEM_Subscription Demand variable is calculated with SSEM_Yearly Usage. The partnership Royalty Revenue variable is linked to the Royalty Rate in partnership pattern.

The SSEM_Development Cost, SSEM_Resource Acquisition Cost for Service element, SSEM Hardware Offering Cost, Marketing Cost and Commission variables constitute cost structure aspect in SSEM profit creation pattern. The SSEM_Developement Cost variable is modelled as the initial value of SSEM's accumulative stock variable because this cost incurred once before the service business proceeds.

\subsection{Simulation result analysis of SSEM business model}

The SSEM system dynamics model was simulated to evaluate its economic sustainability. The values of key variables used in the system dynamics model are explained in this section. The values were determined by market investigation with business experts. The potential customer size of SSEM was determined with target customer size calculated with the number of premium library franchises, the number of premium libraries in each of franchise company and the number of seats in each premium library. The initial value of SSEM_Potential Customer is 0.1 million. The yearly usage of SSEM is assumed to logistically grow with marketing and word of mouth effects.

The SSEM_Development Cost is set as 0.6 billon KRW. The value of SSEM membership price was set to $8,000 \mathrm{KRW}$ which is about 7 USD. LED Lighting production cost of $11,000 \mathrm{KRW}$ and tablet cost of 40,000 KRW were set. Tablets are acquired at the level 10,000 units initially with 4,000 units increase annually considering the depreciation and increasing size of SSEM service users. The partnership royalty rate and commission rate are $8 \%, 5 \%$ respectively.

The result of system dynamics simulation is summarized in Figure 4. Through the simulation results, it is possible to check the characteristics of subscription based PSS business model. In the early stages of the business, the total profit (marked in green line) have negative value which is -600 million KRW due to the initial investment cost for SSEM PSS. Yet, it is confirmed that profit is generated in the 
long term through service sales revenue from subscription fee and additional partnership revenue as the SSEM service yearly usage increased.

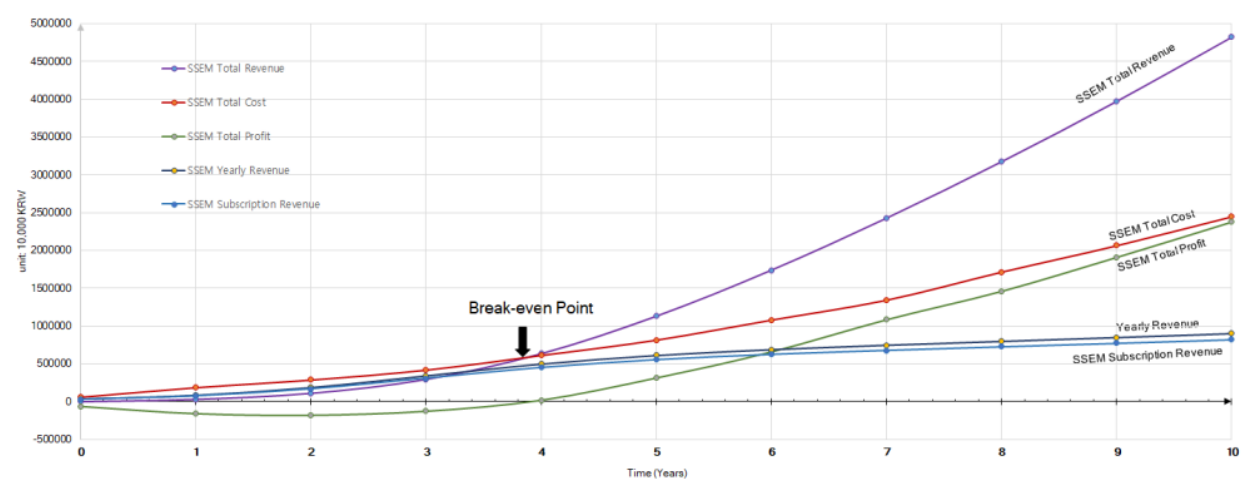

Figure 4. Result of system dynamics simulation

For evaluating economic sustainability of SSEM, the value of KPIs which represented in Table 1 were calculated using the values of stock and flow variables from system dynamics simulation results. Four KPIs are NPV, RoI and B/C Ratio as well as the break-even point (BEP). The KPIs are calculated using formula represented in Park (2008).

Table 1. Value of KPIs for SSEM business model

\begin{tabular}{lcccc}
\hline \multirow{2}{*}{ KPIs } & \multicolumn{4}{c}{ Total business period } \\
\cline { 2 - 5 } & 1 Year & 3 Years & 5 Years & 7 Years \\
\hline NPV (Unit: 10,000 KRW) & $-157,799$ & $-142,666$ & 189,698 & 727,671 \\
\hline RoI (\%) & -83.56 & -29.82 & 38.51 & 80.64 \\
\hline B/C Ratio & 0.164 & 0.702 & 1.385 & 1.806 \\
\hline
\end{tabular}

In case of $\mathrm{B} / \mathrm{C}$ Ratio, the output value is $0.164,0.702,1.385$, and 1.806 at year 1 , year 3 , year 5 , and year 7 respectively. If the $\mathrm{B} / \mathrm{C}$ Ratio is larger than one, the business is judged to have investment feasibility. From the result of the four KPIs, we can check that the KPIs which were poor due to initial investment in SSEM, improve with revenues through SSEM service subscription and partnership royalties. The BEP is about 3.9 years. Overall, as a result of analysing the KPI value, it was confirmed that the SSEM business model is an economically sustainable concept.

\section{CONCLUSION}

To pursue business innovation with PSS, many different PSS concepts are designed and evaluated. Various business models of a PSS design concept are devised and evaluated as well. Evaluation of economic sustainability of PSS business models is critical. This paper presents a systematic method to evaluate economic sustainability of PSS business models using a system dynamics modelling template. System dynamics modelling task is challenging for practitioners due to the variety of variables comprising business model strategies and their complex interrelationships. To enable the modelling task, a system dynamics modelling template composed six patterns of customer acquisition, channel acquisition, profit creation, resource acquisition, PSS provision, and partnership pattern has been devised. The PSS business model evaluation method has been illustrated using a smart study experience management service system design case to demonstrate the proposed system dynamics modelling template can reflect the case specific business model which consist of the particular business model strategies.

The development of system dynamics modelling template using six key patterns for evaluating economic sustainability of complex PSS business models is the main contribution. Particularly six key patterns defined by a divide and conquer approach enables the accommodation of different business model strategies in each aspect in system dynamic modelling. Also, the template which combines the key patterns, can address all the aspects of complex PSS business model simultaneously.

PSS design involves many iterations of PSS concept design and evaluation. Alternative business models are designed for PSS concepts and their evaluations are conducted repeatedly. Economic 
sustainability evaluations reflecting diverse business contexts are also done many times using system dynamics simulations. Thus the proposed systematic evaluation method for PSS business models using the system dynamics model template would play a significant role in evaluating PSS business models and in designing PSS concepts.

\section{REFERENCES}

Chesbrough, H. (2002), "The role of the business model in capturing value from innovation: evidence from Xerox Corporation's technology spin-off companies”, Industrial and Corporate Change, Vol. 11 No. 3 , pp. 529-555.

Costa, N., Patricio, L., Morelli, N., and Magee, C.L. (2018) 'Bringing Service Design to manufacturing companies: Integrating PSS and Service Design approaches', Design Studies, Vol.55, pp.112-145.

Fernandes, S. D. C., Pigosso, D. C. A., McAloone, T. C., Rozenfeld, H. (2020). Towards product-service system oriented to circular economy: A systematic review of value proposition design approaches, Journal of Cleaner Production, 257.

Gemser, G., Kuijken, B., Wijnberg, N.M. and van Erp, J. (2012) 'The Experience of Product-Service Systems', Proceedings of The 8th Design \& Emotion Conference, London.

Goedkoop, M.J., van Halen, C.J,G., te Riele, H.R.M. and Rommens, P.J.M. (1999) Product Service Systems, Ecological and Economic Basics, the Dutch ministries of Environment (VROM) and Economic Affairs (EZ). Hague, The Netherlands.

Kim, Y.S.; Hong, Y.K. (2019) Systematic Method to Design Product-Service Systems Using Personalization Services based on Experience Evaluations, International Journal of Product Development, 23, 353-385.

Kim, Y.S. and Lee, S.W. (2011) 'Service Design for Product-Service Systems using Context-Based Activity Modeling', Proc. of International Association of Societies of Design Research (IASDR), Delft.

Kim, Y.S., Hong, Y.K., Kim, J.H. and Kim, Y.M. (2011) 'Context-Specific Experience Sampling for Experience Design Research', The 18th International Conference on Engineering Design (ICED11), Copenhagen.

Kim Y.S., Jeong J., Hong Y., Hong S.J. (2020) A Schema for Systematic Service Imagining: Context-Based Activity Modeling. Sustainability. 12(22):9558.

Kim, Y.S., Lee, S.W., Jeong, H., Kim, S.R., Kim, J.H., Noh, J.H., and Won, J.H. (2013) 'A Systematic Design Framework for Product-Service Systems and Its Implementation', International Conference on Service Science and Innovation, Kaohsiung.

Lee, J.H., Shin, D.I., Hong, Y.S. and Kim, Y.S. (2011) 'Business Model Design Methodology for Innovative Product-Service Systems: A Strategic and Structured Approach', The 18th International Conference on Engineering Design (ICED11), Copenhagen.

Meier, H., Voelker, O. and Funke, B. (2011) 'Industrial Product-Service Systems', International J. of Advanced Manufacturing Technology, 52, pp.1175-1191.

Morelli, N. (2003) 'Product-Service Systems, a Perspective Shift for Designers: a Case Study: the Design of a Telecentre", Design Studies, Vol. 24(1), pp.73-99.

Nakada, T., Sholihah, M., Mitake, Y. and Shimomura, Y. (2020), "Toward the development of a comprehensive Product-Service System (PSS) evaluation method”, Procedia CIRP, Vol. 93, pp. 802-807.

Osterwalder, A., and Pigneur, Y. (2010) Business Model Generation - A Handbook for Visionaries, Game Changers and Challengers, John Wiley \& Sons, New Jersey.

Park, C.S. (2013), Fundamentals of engineering economics, Pearson Education, Upper Saddle River, NJ, USA.

Park, J. A., \& Kim, Y. S. Visual Reasoning and Design Processes, The 16th International Conference on Engineering Design. Paris, 2007.

Sterman, J.D. (2000) Business Dynamics: Systems Thinking and Modeling for a Complex World, McGraw-Hill Higher Education, New York.

Teece, D.J. (2010), “Business models, business strategy and innovation”, Long Range Planning, Vol. 43 No. 2-3, pp. 172-194.

Tukker, A. (2004) 'Eight Types of Product-Service Systems: Eight Ways to Sustainability? Experiences from SusProNet', Business Strategy and the Environment, Vol. 13, pp.246-260.

Tukker, A. (2015) Product services for a resource-efficient and circular economy - A review, Journal of Cleaner Production, 97, pp. 76-91.

Valencia, A., Mugge, R., Schoormans, J.P.L., \& Schifferstein, H.N.J. (2015) 'The design of smart productservice systems (PSSs): An exploration of design characteristics', International Journal of Design, 9(1), pp.13-28.

Won, J.H.; Kim, Y.S.; Lee, J.H.; Hong, Y.S. (2014) Association of Product-Service Systems design concepts with business models and their evaluation method, IEEE International Conference on Engineering, Technology and Innovation (ICE), Bergamo.

Zott, C., Amit, R. and Massa, L. (2011), "The Business Model: Recent Developments and Future Research", Journal of Management, SAGE Publications Inc, Vol. 37 No. 4, pp. 1019-1042. 